\title{
Is It All Clear if Procalcitonin Clears in Acute Pancreatitis?
}

\author{
Subramani Kandasamy \\ Indian Journal of Critical Care Medicine (2020): 10.5005/jp-journals-10071-23388
}

The natural course of acute pancreatitis (AP) begins with an acute inflammatory response that lasts for up to 10 days. Milder forms constitute about $80 \%$, which may not progress further with appropriate support organ dysfunction associated with this stage, while the severe form is seen in about $20 \%$ with an associated mortality of $40 \%{ }^{1}$ Beyond the acute phase, complications, namely, infection and organ failure can arise, which can prolong the illness for months, leading to an increased mortality (40\%). If patients likely to progress from moderately severe to severe pancreatitis can be identified early, close monitoring and aggressive treatment could be instituted to improve the outcome. This may involve transfer to advanced centers and would help in optimal resource allocation.

Severity of illness scoring systems and biomarkers have been used alone or in combination to classify the severity of pancreatitis and predict outcome with varying success. ${ }^{2,3}$ Scoring systems can be general such as acute physiology and chronic health evaluation (APACHE), systemic inflammatory response syndrome (SIRS), or organ-specific such as bedside index of severity in acute pancreatitis (BISAP), Ranson's score, Glasgow score, pancreatitis assessment scoring system (PASS), etc. By definition, APACHE is calculated 24 hours into intensive care unit (ICU) admission. The most commonly used scoring system is APACHE II, and the current literature shows a cutoff value of 8 . Hence, it is a reliable predictor of outcome. ${ }^{4}$ Chatzicostas et al. compared Ranson's score, APACHE II, and III and found all the three had similar predictability. ${ }^{5}$ Recently, APACHE II and APACHE IV scores have been compared with a cutoff of 8 and 45 , respectively, and the latter has a better diagnostic capacity than APACHE II, BISAP, and Ranson's criteria. ${ }^{6}$

In milder forms, markers with anti-inflammatory properties such as interleukin-10 (IL10) and in more severe forms, markers with proinflammatory properties IL1, IL6, IL8, and platelet activating factor (PAF), to name a few, are detected in higher concentrations. C-Reactive protein (CRP) is a marker secreted by the liver and thyroid during inflammation, and a level $\geq 150 \mathrm{mg} / \mathrm{L}$ has been suggested to be a good prognostic marker by day 3 of illness. ${ }^{1}$ Procalcitonin (PCT), the inactive form of the hormone calcitonin, is secreted by the hepatocytes and the $C$ cells of the thyroid gland and has been shown to be a good marker for bacterial sepsis. However, the levels are elevated by modest levels in other noninfectious inflammatory conditions too. In AP, it has been shown to be elevated and equivalent or a better marker than CRP (cutoff of $1.77 \mathrm{ng} / \mathrm{mL}$ ). ${ }^{7}$ Mofidi et al. in a systematic review have shown that the sensitivity and specificity of PCT for the development of severe AP were $72 \%$ and $86 \%$, respectively, with a cutoff value of $0.5 \mathrm{ng} / \mathrm{mL}$ and the overall area under the curve was $0.87 .^{8}$

In trauma, with aseptic systemic inflammation-a scenario similar to early AP, the PCT levels increase by day 1 and then fall rapidly. However, in case of an associated infection, the PCT levels increase. Procalcitonin clearance has been studied as a prognostic marker in sepsis and septic shock. Suberviola et al.
Division of Critical Care, Christian Medical College, Vellore, Tamil Nadu, India

Corresponding Author: Subramani Kandasamy, Division of Critical Care, Christian Medical College, Vellore, Tamil Nadu, India, Phone: +919486046929, e-mail: ksubramani9@hotmail.com

How to cite this article: Kandasamy S. Is It All Clear if Procalcitonin Clears in Acute Pancreatitis? Indian J Crit Care Med 2020;24(3):149-150. Source of support: Nil

Conflict of interest: None

have shown that PCT clearance of $70 \%$ is a better marker than CRP and leukocyte count clearance for mortality prediction. ${ }^{9}$ Schuetz et al. have shown that in sepsis, PCT clearance of $80 \%$ from baseline by day 4 is associated with reduction in mortality, which otherwise doubles. ${ }^{10}$

In this issue, the Choudhuri et al. ${ }^{11}$ have reported a prospective observational study comparing change in APACHE II score and PCT levels in patients admitted with pancreatitis. The admission APACHE and PCT were compared to APACHE and PCT at 48 hours of admission. Procalcitonin concentrations decreased in survivors and APACHE II score increased in nonsurvivors, and the change was more significant for PCT. The novelty of the study is the quantification of the change in PCT and APACHE II. This study is a single-center study with small sample size, and a larger multicenter study with quantification of change in both APACHE II score and PCT will be more useful.

The need of the hour is either a low cost marker or an easily calculable score at ICU admission to predict prognosis and guide treatment. The point-of-care PCT which is now available can be a good substitute in this regard.

\section{References}

1. Leppäniemi A, Tolonen M, Tarasconi A, Segovia-Lohse H, Gamberini E, Kirkpatrick AW, et al. 2019 WSES guidelines for the management of severe acute pancreatitis. World J Emerg Surg 2019;14:27. DOI: 10.1186/s13017-019-0247-0.

2. Khanna AK, Meher S, Prakash S, Tiwary SK, Singh U, Srivastava A, et al. Comparison of Ranson, glasgow, MOSS, SIRS, BISAP, APACHE-II, CTSI scores, IL-6, CRP, and procalcitonin in predicting severity, organ failure, pancreatic necrosis, and mortality in acute pancreatitis. HPB Surg 2013;2013:367581. DOI: 10.1155/2013/367581.

3. Liang Y, Zhao X, Meng F. Procalcitonin, C-reactive protein, and neutrophil ratio contribute to the diagnosis and prognosis of severe acute pancreatitis. Iran J Public Health 2019;48(12):2177-2186.

4. Harshit Kumar A, Singh Griwan M. A comparison of APACHE II, BISAP, Ranson's score and modified CTSI in predicting the severity of acute pancreatitis based on the 2012 revised Atlanta Classification. Gastroenterol Rep (Oxf) 2018;6(2):127-131. DOI: 10.1093/gastro/ gox029.

(0) The Author(s). 2020 Open Access This article is distributed under the terms of the Creative Commons Attribution 4.0 International License (https://creativecommons. org/licenses/by-nc/4.0/), which permits unrestricted use, distribution, and non-commercial reproduction in any medium, provided you give appropriate credit to the original author(s) and the source, provide a link to the Creative Commons license, and indicate if changes were made. The Creative Commons Public Domain Dedication waiver (http://creativecommons.org/publicdomain/zero/1.0/) applies to the data made available in this article, unless otherwise stated. 
5. Chatzicostas C, Roussomoustakaki M, Vlachonikolis IG, Notas G, Mouzas I, Samonakis D, et al. Comparison of Ranson, APACHE II and APACHE III scoring systems in acute pancreatitis. Pancreas 2002;25(4):331-335. DOI: 10.1097/00006676-20021100000002.

6. Mok SRS, Mohan S, Elfant AB, Judge TA. The acute physiology and chronic health evaluation IV, a new scoring system for predicting mortality and complications of severe acute pancreatitis. Pancreas 2015;44(8):1314-1319. DOI: 10.1097/MPA.0000000000000432.

7. Silva-Vaz P, Abrantes AM, Castelo-Branco M, Gouveia A, Botelho MF, Tralhão JG. Multifactorial scores and biomarkers of prognosis of acute pancreatitis: applications to research and practice. Int J Mol Sci 2020;21(1):338. DOI: 10.3390/ijms21010338.

8. Mofidi R, Suttie SA, Patil PV, Ogston S, Parks RW. The value of procalcitonin at predicting the severity of acute pancreatitis and development of infected pancreatic necrosis: systematic review. Surgery 2009;146(1):72-81. DOI: 10.1016/j.surg.2009. 02.013.

9. Suberviola B, Castellanos-Ortega A, González-Castro A, GarcíaAstudillo LA, Fernández-Miret B. Prognostic value of procalcitonin, C-reactive protein and leukocytes in septic shock. Med Intensiva 2012;36(3):177-184. DOI: 10.1016/j.medin.2011.09.008.

10. Schuetz $P$, Birkhahn $R$, Sherwin $R$, Jones $A E$, Singer $A$, Kline JA, et al. Serial procalcitonin predicts mortality in severe sepsis patients: results from the multicenter procalcitonin monitoring sepsis (MOSES) study. Crit Care Med 2017;45(5):781-789. DOI: 10.1097/ CCM. 0000000000002321 .

11. Choudhuri AH, Duggal S, Biswas PS, Uppal R. A Comparison of Acute Physiology and Chronic Health Evaluation II Score and Serum Procalcitonin Change for Predicting Mortality in Acute Pancreatitis. Indian J Crit Care Med 2020;24(3):190-194. 